\title{
Phytochemical study guided by the myorelaxant activity of the crude extract, fractions and constituent from stem bark of Hymenaea courbaril $\mathrm{L}$.
}

\author{
Gabrieli Penha Bezerra ${ }^{\mathrm{a}, \mathrm{c}, *}$, Roberto Wagner da Silva Góis ${ }^{\mathrm{b}}$, \\ Teresinha Silva de Brito ${ }^{\mathrm{d}}$, Francisco José Batista de Lima ${ }^{\mathrm{d}}$, Mary Anne \\ Medeiros Bandeira ${ }^{\mathrm{a}, \mathrm{c}}$, Nirla Rodrigues Romero ${ }^{\mathrm{c}}$, Pedro Jorge Caldas Magalhães ${ }^{\mathrm{a}, \mathrm{d}}$, \\ Gilvandete Maria Pinheiro Santiago a,b,c
}

a Programa de Pós-Graduação em Ciências Farmacêuticas, Faculdade de Farmácia, Odontologia e Enfermagem, Universidade Federal do Ceará, Brazil

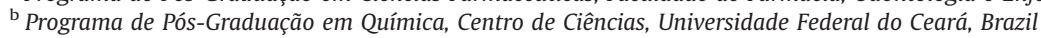

${ }^{\mathrm{c}}$ Departamento de Farmácia, Universidade Federal do Ceará, Brazil

d Programa de Pós-Graduação em Farmacologia, Departamento de Fisiologia e Farmacologia, Faculdade de Medicina, Universidade Federal do Ceará, Brazil

\section{A R T I C L E I N F O}

\section{Article history:}

Received 16 February 2013

Received in revised form

24 May 2013

Accepted 31 May 2013

Available online 10 June 2013

\section{Keywords:}

Hymenaea courbaril L.

Antioxidant activity

Myorelaxant activity

Anti-inflammatory activity

\begin{abstract}
A B S T R A C T
Ethnopharmacological relevance: Hymenaea courbaril L. (Caesalpinoideae) is used in Brazilian folk medicine to treat anemia, kidney problems, sore throat and other dysfunctions of the respiratory system, such as bronchitis and asthma, although such properties are yet to be scientifically validated.

Aim of the study: In order to give a scientific basis to support the traditional use of Hymenaea courbaril, this study was designed to evaluate antioxidant, myorelaxant and anti-inflammatory properties of the ethanol extract from stem bark and its fractions. The myorelaxant effect of astilbin, a flavonoid isolated from the bioactive ethyl acetate fraction (EAF), has also been evaluated.

Material and methods: In the present study ethanol extract from stem bark (EEHC) and fractions were analyzed using bioassay-guided fractionation. The following activities were investigated: antioxidant by 2,2-diphenyl-1picrylhydrazyl (DPPH) assay, myorelaxant on rat tracheal smooth muscle, and anti-inflammatory using ovalbumin-induced leukocytosis and airway hyperresponsiveness in rats.

Results: The results of the present investigation show that the whole extract of Hymenaea courbaril and some of its fractions strongly scavenged DPPH radical. The extract showed myorelaxant activity on rat trachea, being EAF its highest efficient fraction. Bio-guided study allowed the isolation of astilbin, a well-known flavonoid. The activity induced by this compound indicates that it may be partly responsible for the myorelaxant effect of EAF. EAF reduced contractions that depended on divalent cation inflow through voltage-operated $\mathrm{Ca}^{2+}$ channels (VOCCs) or receptor-operated $\mathrm{Ca}^{2+}$ channels (ROCCs), but it was more potent to inhibit VOCC- than ROCCdependent contraction induced by $\mathrm{Ca}^{2+}$ addition in $\mathrm{ACh}$-enriched $\mathrm{Ca}^{2+}$-free medium. Oral pretreatment of antigen-challenged animals with EAF prevented airway hyperresponsiveness on KCl-induced contraction and reduced the number of total white cells, particularly eosinophils and neutrophils in bronchoalveolar lavage. Conclusions: This study provided scientific basis that Hymenaea courbaril presents potential antioxidant, myorelaxant and anti-inflammatory actions, which support its use in folk medicine to treat inflammatory airway diseases.
\end{abstract}

\footnotetext{
Abbreviations: ACh, acetylcholine; AcOEt, ethyl acetate; BALF, bronchoalveolar lavage fluid; $\mathrm{CCh}$, carbachol; $\mathrm{CH}_{2} \mathrm{Cl}_{2}$, dichloromethane; DEAF, dichloromethane: ethyl acetate fraction; DF, dichloromethane fraction; DPPH, 1,1-diphenyl-1-picrylhydrazyl; EAF, ethyl acetate fraction; EEHC, Hymenaea courbaril stem bark ethanol extract; HDF, hexane:dichloromethane fraction; Hex, hexane; HF, hexane fraction; $\mathrm{MeOH}$, methanol; MF, methanol fraction; NMR, nuclear magnetic resonance; OVA, ovalbumin; ROCCs, receptor-operated $\mathrm{Ca}^{2+}$ channels; TLC, thin layer chromatography; VOCCs, voltage-operated $\mathrm{Ca}^{2+}$ channels

* Corresponding author at: Universidade Federal do Ceará, Departamento de Farmácia, Rua Capitão Francisco Pedro, 1210, 60430370 Fortaleza, Ceará, Brazil. Tel.: +558533668279.

E-mail address: gabrielipb@gmail.com (G.P. Bezerra).
}

\section{Introduction}

The genus Hymenaea (Fabaceae, Caesalpinioideae) includes fourteen species, nine of them found in several regions in Brazil including the lowland tropical ecosystems that follow uniform distribution in the Amazon forest (Lee and Langenheim, 1975; Campos and Uchida, 2002). Most species of this genus has economic value by providing high quality wood, resins, fruits and edible barks rich in tannins, a fact which justifies their use in folk medicine. Hymenaea courbaril L., popularly known in Brazil 
as "jatobá", is a tree whose leaves, roots, fruits, and especially the stem bark are traditionally employed in folk medicine by means of infusions and decoctions to treat anemia, kidney problems, sore throat and other airway diseases such as bronchitis and asthma (Cartaxo et al., 2010).

Beyond the presence of polyphenolic constituents, several other compounds - mainly enantio-labdanoic and enantio-halimane type diterpenes and sesquiterpenes - have been isolated from the seed pods (Nogueira et al., 2001; Jayaprakasam et al., 2007), stem bark (Nogueira et al., 2002), trunk resin (Cunningham et al., 1974; Marsaioli et al., 1975), and the peel of the ripe fruits (Aguiar et al., 2010) of Hymenaea courbaril. Chemical analysis of the yellowish sweet powder obtained from its fruits yielded sucrose and linolenic acid (Jayaprakasam et al., 2007). Furthermore, the sesquiterpenes $\alpha$-copaene, spathulenol and $\beta$-selinene were identified in the essential oil from the peel of the ripe fruits, while germacrene-D, $\beta$-caryophyllene and bicyclogermacrene were the major compounds in the oil from unripe fruits (Aguiar et al., 2010).

So diverse chemical composition may provide the known antioxidant, anti-inflammatory (Jayaprakasam et al., 2007), antiviral (Cecílio et al., 2012) and anticancer (Keiji et al., 1999) properties already reported to extracts, fractions or compounds isolated from Hymenaea courbaril. The essential oil obtained from the peel of the fruits also possesses strong larvicidal activity against Aedes aegypti (Aguiar et al., 2010).

Considering the importance of Hymenaea courbaril L. to Brazilian folk medicine, the present work was carried out to establish the antioxidant, anti-inflammatory and myorelaxant effects of this species through bioassay-guided fractionation of the ethanol extract of the stem bark, describing the isolation and identification of a known flavonoid astilbin, in order to scientifically support its properties and medicinal use.

\section{Material and methods}

\subsection{Plant material}

The stem bark of Hymenaea courbaril L. was collected in April 2011 in Crato, State of Ceará, Brazil. The botanical identification was obtained by comparison with a voucher specimen (\#EAC 49901 ) deposited at the Prisco Bezerra Herbarium, Departamento de Biologia, Universidade Federal do Ceará, Ceará, Brazil.

\subsection{Animals}

Male wistar rats (200-300 g) were housed under standard conditions with free access to food and water at the vivarium of the Universidade Federal do Ceará, being the study protocol submitted to and approved by its local Animal Ethics Committee (protocol no. \#37/12).

\subsection{Solutions and drugs}

The physiological salt solution was a modified Krebs-Henseleit solution of the following composition: $118.0 \mathrm{mM} \mathrm{NaCl}, 4.7 \mathrm{mM} \mathrm{KCl}$,

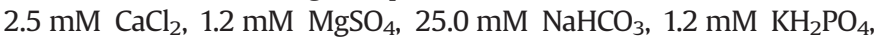
and $10.0 \mathrm{mM}$ glucose. Solutions with a high $\mathrm{KCl}$ content were prepared by adding $\mathrm{KCl}$ to the bath from a $3 \mathrm{M} \mathrm{KCl}$ solution in distilled water.

Carbachol (CCh), acetylcholine (ACh), verapamil, glycol ether diamine tetraacetic acid (EGTA), 2,2-diphenyl-1-picrylhydrazyl (DPPH), ovalbumin, pentobarbital were purchased from Sigma (St. Louis, USA), and deuterated methanol from Tedia (Ohio, USA).
Salts, reagents and solvents (all of analytical grade) were purchased from Sigma or Merck (Darmstadt, Germany).

\subsection{Preliminary phytochemical screening}

The phytochemical profile was determined following the procedures described by Matos (2009), in which the identification reactions were based on the presence of chemical groups or revealed by thin layer chromatography (TLC).

\subsection{Preparation of the extract, bioassay-guided fractionation and astilbin isolation}

Air-dried stem barks of Hymenaea courbaril (500 g) were triturated and subjected to exhaustive extraction by conventional maceration with ethanol $(13 \times 1 \mathrm{~L})$ at room temperature for a period of 7 days. After filtration, the solvent was removed at $40{ }^{\circ} \mathrm{C}$ under reduced pressure, to yield $86 \mathrm{~g}$ of an ethanol extract of Hymenaea courbaril (EEHC). After evaluation of the myorelaxant activity, EEHC was submitted to bioassay-guided fractionation in column chromatography over silica gel (Merck 60-120 mesh) using hexane (Hex), dichloromethane $\left(\mathrm{CH}_{2} \mathrm{Cl}_{2}\right)$, ethyl acetate (AcOEt) and methanol $(\mathrm{MeOH})$ employed pure, or in binary mixtures (1:1) according to the polarity profile of the eluent, which resulted in 6 fractions (yield values are shown as percentage $\mathrm{w} / \mathrm{w}$ of the whole extract weight): hexane (HF; 0.094\%), hexane:dichloromethane (HDF; 0.25\%), dichloromethane (DF; 1.62\%), dichloromethane:ethyl acetate (DEAF; 1.25\%), ethyl acetate (EAF; 2.41\%) and methanol (MF; 76.68\%) fractions. HF and HDF were not submitted to bioassays due to their low yield on chromatographic treatment.

Except for those showing low yield (HF and HDF), fractions were then pharmacologically tested in isolated preparations of rat trachea contracted with either CCh or with a high $\mathrm{K}^{+}$concentration $(60 \mathrm{mM})$. Once identified a given bioactive fraction (EAF), $1.5 \mathrm{~g}$ of EAF were subjected to column chromatography using silica gel (as the stationary phase), eluted initially with hexane followed by more polar eluents, such as dichloromethane, ethyl acetate and methanol. In total, 230 fractions ( $5 \mathrm{~mL}$ each) were collected and analyzed by TLC. Those showing a similar result were combined. The fraction 180-189 (49.6 mg), by revealing apparent low chemical complexity in TLC, was solubilized in acetone and their soluble part (37.3 mg) was submitted to chromatography on Sephadex LH 20 with $\mathrm{MeOH}$, yielding 26 fractions ( $2 \mathrm{~mL}$ each), that were analyzed by TLC. The subfraction $11-15$ (30.3 mg, yield $2.02 \% \mathrm{w} / \mathrm{w}$; percentage of the EAF weight) named HCC-4 was submitted to NMR analysis, which allowed the identification of astilbin.

\subsection{Evaluation of the antioxidant properties of Hymenaea courbaril extract and fractions}

The antioxidant activity of the extract and fractions were evaluated by measuring the reduction of the free radical 1 , 1-diphenyl-1-picrylhydrazyl (DPPH). The samples (1.0 to $1000.0 \mu \mathrm{g} /$ $\mathrm{mL}$ ) were dissolved in methanol and then added to a methanol solution of DPPH $(60 \mu \mathrm{M})$. After $30 \mathrm{~min}$., the UV absorbance of the resulting solutions was recorded at $\lambda 517 \mathrm{~nm}$ (Brandy-Williams et al., 1995). The experiment was performed in triplicate and the average absorption was noted for each concentration. Trolox was used as the positive control. The free radical scavenging activity was calculated as a percentage inhibition of the DPPH radical by the sample or positive control. The $\mathrm{IC}_{50}$ value is the concentration required to scavenge $50 \% \mathrm{DPPH}$. 


\subsection{Preparation of rat trachea rings}

After the animal euthanasia, performed by intraperitoneal (i.p.) injection of concentrated sodium pentobarbital, the trachea was dissected out and placed into a dish containing physiological salt solution ( $\mathrm{pH} 7.4$ ) to allow the careful removal of adherent fat and connective tissue. Next, the trachea was cut transversely into cylindrical rings (including 3-4 cartilage rings in each section), which were suspended in a $5 \mathrm{~mL}$ organ bath containing physiological solution maintained (at $37^{\circ} \mathrm{C}$; pH 7.4) continuously aerated by bubbling a mixture of $5 \% \mathrm{CO}_{2}$ in $\mathrm{O}_{2}$. Tracheal rings were suspended using a pair of stainless steel triangular pieces passed through the lumen, following a parallel arrangement. For tension measurements one of the steel pieces was connected to the force transducer, while the other was connected to a fixed pin in the bath allowing the establishment of a passive tension of $1 \mathrm{~g}$. Under such disposal, the devices were connected to a data aquisition system (PowerLab ADInstruments, Australia) to enable isometric tension recordings on a microcomputer. Tissues were allowed to equilibrate for $1 \mathrm{~h}$ before each experiment. In all experiments, to evaluate the tissue viability after the equilibration period, $60 \mathrm{mM}$ $\mathrm{K}^{+}$-induced reference contractions were elicited and when contractile responses appeared with similar magnitude, preparation was considered fully functional. Tissues without reproducible contractions were discarded.

\subsection{Effects of extract, fractions and isolated compound on CCh or KCl-induced contractions}

After the stabilization period, the tracheal relaxation was carried out following the cumulative addition of EEHC, its fractions or the isolated compound astilbin $(1-1000 \mu \mathrm{g} / \mathrm{mL})$, added on the steady state of sustained contractions induced by CCh $(1 \mu \mathrm{M})$ or $\mathrm{KCl}(60 \mathrm{mM})$. Relaxation was measured and expressed as percentage of the contraction induced by $\mathrm{CCh}$ or $\mathrm{KCl}$ alone. Afterwards, the tissue was washed by successive changes $(5 \times)$ of the solution within the bath chamber, in order to remove the test substances and bring the $\mathrm{K}^{+}$concentration to its physiological levels. Then, a new $60 \mathrm{mM} \mathrm{K} \mathrm{K}^{+}$-induced contraction was elicited to verify the tissue responsiveness after its exposure to the extract or to a given bioactive fraction.

2.9. Effects of the bioactive fraction of Hymenaea courbaril (EAF) on the contractions induced by $\mathrm{Ca}^{2+}$ or $\mathrm{Ba}^{2+}$ in tracheal rings maintained under $\mathrm{Ca}^{2+}$-free conditions in presence of acethylcholine

After the equilibration period, tracheal rings were exposed to $\mathrm{Ca}^{2+}$-free conditions (in presence $1 \mathrm{mM}$ of the $\mathrm{Ca}^{2+}$-chelating compound EGTA and $10 \mu \mathrm{M}$ of the L-type $\mathrm{Ca}^{2+}$ channel blocker verapamil) and then stimulated with acetylcholine (ACh; $10 \mu \mathrm{M}$ ). Such procedure produced a transient contraction that rapidly returned to the baseline. Afterwards, concentration-response curves were constructed by cumulative addition of $\mathrm{CaCl}_{2}(0.1-50 \mathrm{mM})$ in the absence or in the presence of EAF (300 or $600 \mu \mathrm{g} / \mathrm{mL}$ ). To evaluate the effects of the bioactive fraction of Hymenaea courbaril on contractions induced by an electromechanical coupling, concentration-response curves were constructed by adding cumulatively $\mathrm{Ba}^{2+}(0.1-50 \mathrm{mM})$ into $\mathrm{Ca}^{2+}$-free medium enriched with $60 \mathrm{mM} \mathrm{K}^{+}$in the absence or in the presence of EAF or verapamil $(10 \mu \mathrm{M})$, used as positive control.

2.10. Sensitization procedures and antigenic challenge by ovalbumin inhalation

To investigate the effects of EAF on the hyperresponsive phenotype of tracheal rings from sensitized animals submitted to antigenic challenge, rats were actively sensitized to ovalbumin (OVA; chicken egg albumin; grade II; Sigma, USA; $10 \mathrm{mg} / \mathrm{kg}$ ) on days 1,3 , and 5 by an i.p. injection of OVA diluted in saline solution (sterile $0.9 \% \mathrm{NaCl} ; 0.5 \mathrm{~mL}, 10 \mathrm{mg} / \mathrm{kg}$, once per day). Separate groups of conscious rats sensitized to OVA were challenged by inhalation of OVA (first challenge $1 \mathrm{mg} / \mathrm{mL}$; second challenge $5 \mathrm{mg} / \mathrm{mL}$; $15 \mathrm{~min}$ each) via an ultrasonic nebulizer (RespiraMax; NS Indústria de Aparelhos Médicos, São Paulo, Brazil) 15 min after receiving oral treatment with $\mathrm{EAF}(150 \mathrm{mg} / \mathrm{kg})$ or saline. All animals were euthanized $12 \mathrm{~h}$ later and tracheal rings were disposed in bath chamber as already described in order to evaluate the contractile responses induced by the increasing concentrations of $\mathrm{KCl}(10-140 \mathrm{mM})$. In the present experimental protocol, the animals were divided in groups as follows:

Group I: OVA-sensitized animals challenged with saline Group II: OVA-sensitized animals challenged with OVA Group III: OVA-sensitized animals challenged with OVA after pretreatment with EAF $(150 \mathrm{mg} / \mathrm{kg})$

\subsection{Effects of bioactive fraction (EAF) on the concentration- response curve to $\mathrm{KCl}$ in OVA-challenged rat tracheal rings}

Tracheal rings obtained from OVA-sensitized animals challenged with saline (group I), OVA or with OVA preceded by pretreatment with EAF (group III and II, respectively) were, $12 \mathrm{~h}$ later, suspended in organ baths according to item 2.7. Cumulative concentration-response curves were then constructed by exposing preparations to increasing concentrations of $\mathrm{KCl}(10-140 \mathrm{mM})$.

\subsection{Effects of bioactive fraction (EAF) on total and differential cell count in bronchoalveolar lavage fluid of OVA-challenged rats}

Bronchoalveolar lavage fluid (BALF) was also obtained by two repeated washes using $5 \mathrm{~mL}$ of warmed $\left(37^{\circ} \mathrm{C}\right)$ deoxygenated saline, which was surgically introduced into the rat lungs via tracheal cannula connected to a $5 \mathrm{~mL}$ syringe immediately after the animal euthanasia. The BALF was stored in tubes for use in cell count, being then centrifuged (at $4{ }^{\circ} \mathrm{C}, 10 \mathrm{~min}$., 200g). Cells were resuspended in $2 \mathrm{~mL}$ of heparinized saline (1:1000). Pelleted cells were counted in Turk (1:20) stained samples placed in a haemocytometer (Neubauer counting chamber, Inlab, Ribeirão Preto, Brazil). The remaining aliquot was centrifuged again (400g, $10 \mathrm{~min}$ ) and cells were stained with haematoxylin and eosin $(\mathrm{H} \& \mathrm{E})$ for examination by light microscopy (magnification $\times 100$ ) to determine cell differentials.

\subsection{Data analysis}

Data are expressed as mean \pm S.E.M. The results were statistically analyzed using analysis of variance (ANOVA) and $t$-test followed by Holm-Sidak or Rank Sum test, as appropriate. Statistical significance was accepted when $p<0.05$.

\section{Results}

\subsection{Preliminary phytochemical screening and identification of HCC-4}

Preliminary phytochemical analysis of the extract obtained from stem bark of Hymenaea courbaril revealed the presence of polyphenols, such as flavonoids and tannins; as well as anthocyanins, saponins and terpenoids. HCC-4 (Fig. 1) was isolated from the bioactive fraction (EAF) and $1 \mathrm{D}^{1} \mathrm{H}$ and ${ }^{13} \mathrm{C}(\{1 \mathrm{H}\}$ and DEPT) and $2 \mathrm{D}$ 


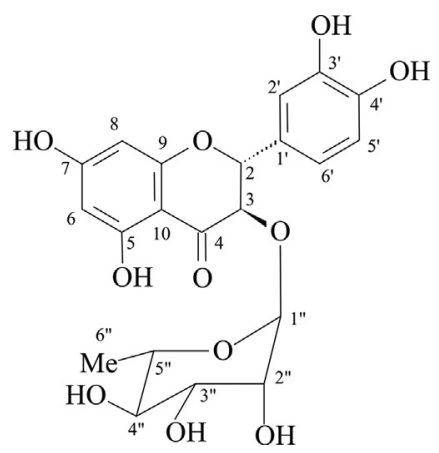

Fig. 1. (A) Chemical structure of astilbin.

${ }^{1} \mathrm{H}-{ }^{1} \mathrm{H}-\mathrm{COSY}, \mathrm{HSQC}$ and HMBC NMR spectral data (Table 1 ) of this compound were in accordance with previously published results for astilbin (Lucas-Filho et al., 2010).

Polarimetric analysis indicated value of specific optical rotation $[\alpha]_{D}{ }^{25}-29.4^{\circ}(c=0.1, \mathrm{MeOH})$. This finding suggests that the absolute configuration $R, R$ for the carbons $\mathrm{C}-2$ and $\mathrm{C}-3$ is present in the molecular structure of astilbin, being this value compatible with that already described in the literature (Regasini et al., 2008).

\subsection{Antioxidant activity}

The extract and its fractions showed antioxidant activity by inhibiting DPPH. EEHC, EAF and MF strongly scavenged DPPH radical with $\mathrm{IC}_{50}$ values of $3.07 \pm 0.18, \quad 5.05 \pm 1.5$ and $5.12 \pm 0.73 \mu \mathrm{g} / \mathrm{mL}$, respectively. Trolox, used as positive control, showed an $\mathrm{IC}_{50}$ value of $2.6 \pm 0.23 \mu \mathrm{g} / \mathrm{mL}$ (Table 2 ).

\subsection{Effects of the extract, fractions and astilbin (HCC-4) on CCh or $\mathrm{KCl}$-induced contractions}

The cumulative addition of EEHC partially relaxed the rat tracheal rings, previously contracted by either $\mathrm{CCh}(1 \mu \mathrm{M})$ or $\mathrm{KCl}$ $(60 \mathrm{mM}$ ) with maximal values of relaxation (for EEHC $1000.0 \mu \mathrm{g} /$ $\mathrm{mL}$ ) corresponding to $43.7 \pm 8.7 \%$ and $52.5 \pm 8.9 \%$, respectively (Fig. 2A and B). Interestingly, the fractions DF, DEAF and MF also partially relaxed tracheal rings contracted with either $\mathrm{CCh}$ or $\mathrm{K}^{+}$, while EAF fully relaxed such contractions (maximal relaxations values of $95.2 \pm 2.9 \%$ in tissues contracted with $\mathrm{CCh}$ and $100.0 \pm 4.1 \%$ in those under stimulation with $\mathrm{K}^{+}$(Table 3 ). Furthermore, EAF more potently inhibited the contractions induced by $\mathrm{K}^{+}\left(\mathrm{IC}_{50}[95 \%\right.$ confidence interval] of $110.6[77.1-158.6 \mu \mathrm{g} / \mathrm{mL}] ; n=7)$ than those ones elicited by CCh $\left(\mathrm{IC}_{50}\right.$ of 287.1 [157.8-523.2 $\left.\mu \mathrm{g} / \mathrm{mL}\right]$; $n=5 ; p<0.05$, Mann-Whitney) (Fig. 2). The maximal relaxation induced by astilbin, a flavonoid isolated from EAF, reached a value of $49.8 \pm 5.5 \%$ of the contraction induced by $60 \mathrm{mM} \mathrm{K}^{+}$(Fig. 3).

The relaxant effect of EEHC was reversible following washout with physiological solution, since subsequent addition of $60 \mathrm{mM} \mathrm{K}^{+}$produced a contractile response equivalent to $104.71 \pm 10.63 \%$ of the $\mathrm{K}^{+}$-induced contraction observed at the initial procedures in these experiments. On the other hand, the addition of $60 \mathrm{mM} \mathrm{K}^{+}$after exposure to EAF produced a contractile response significantly lower $(p<0.001, t$ test) that corresponded only to $3.19 \pm 0.97 \%$ of the reference contraction induced by $\mathrm{K}^{+}$, performed at the beginning of the experiment (Fig. 4).

\subsection{Effects of bioactive fraction (EAF) on contractions induced by $\mathrm{Ca}^{2}$ ${ }^{+}$or $\mathrm{Ba}^{2+}$ in the presence of acethylcholine in $\mathrm{Ca}^{2+}$-free medium}

In preparations maintained under $\mathrm{Ca}^{2+}$-free conditions in the presence of $\mathrm{ACh}(10 \mu \mathrm{M})$ and verapamil $(10 \mu \mathrm{M})$, EAF at a concentration of $300 \mu \mathrm{g} / \mathrm{mL}$ had no significant effect on the concentration-response
Table 1

${ }^{1} \mathrm{H}-{ }^{13} \mathrm{C}$ NMR $\left({ }^{1} \mathrm{JCH}, n=1,2\right.$ and 3 ) spectroscopic data of astilbin in $\mathrm{CD}_{3} \mathrm{OD}$. Chemical shifts in $\delta$ and $J(\mathrm{~Hz})$.

\begin{tabular}{|c|c|c|c|c|}
\hline & \multicolumn{2}{|l|}{ HSQC } & \multicolumn{2}{|l|}{ НMBC } \\
\hline & $\delta_{\mathrm{C}}$ & $\delta_{\mathrm{H}}$ & ${ }^{2} J_{\mathrm{CH}}$ & ${ }^{3} J_{\mathrm{CH}}$ \\
\hline \multicolumn{5}{|l|}{$\mathbf{C}$} \\
\hline 4 & 196.11 & & $\mathrm{H}-3$ & $\mathrm{H}-2$ \\
\hline 5 & 165.64 & & $\mathrm{H}-6$ & \\
\hline 7 & 168.76 & & $\mathrm{H}-6, \mathrm{H}-8$ & \\
\hline $8^{\mathrm{a}}$ & 164.24 & & $\mathrm{H}-8$ & $\mathrm{H}-2$ \\
\hline $4^{\mathrm{a}}$ & 102.64 & & & $\mathrm{H}-6, \mathrm{H}-8$ \\
\hline $1^{\prime}$ & 129.33 & & $\mathrm{H}-2, \mathrm{H}-6^{\prime}$ & $\mathrm{H}-3$ \\
\hline $3^{\prime}$ & 146.68 & & $\mathrm{H}-2$ & $\mathrm{H}-5^{\prime}$ \\
\hline $4^{\prime}$ & 147.51 & & $\mathrm{H}-5^{\prime}$ & $\mathrm{H}-2^{\prime}, \mathrm{H}-6^{\prime}$ \\
\hline \multicolumn{5}{|l|}{ CH } \\
\hline 2 & 84.09 & $5.08, d, 10.6$ & $\mathrm{H}-3$ & $\mathrm{H}-2^{\prime}, \mathrm{H}-6^{\prime}$ \\
\hline 3 & 78.72 & $4.57, d, 10.7$ & $\mathrm{H}-2$ & $\mathrm{H}-1^{\prime \prime}$ \\
\hline 6 & 97.54 & $5.92, d, 2.2$ & & $\mathrm{H}-8$ \\
\hline 8 & 96.42 & $5.90, d, 2.1$ & & H-6 \\
\hline $2^{\prime}$ & 115.65 & $6.96, d, 1.7$ & & $\mathrm{H}-2$ \\
\hline $5^{\prime}$ & 116.49 & 6.82, sl & & \\
\hline $6^{\prime}$ & 120.63 & $6.83, d, 1.9$ & & $\mathrm{H}-2$ \\
\hline $1^{\prime \prime}$ & 102.29 & $4.06, d, 1.7$ & & $\mathrm{H}-3$ \\
\hline $2^{\prime \prime}$ & 71.92 & $3.54, d d, 3.2,1.7$ & & \\
\hline $3^{\prime \prime}$ & 72.32 & $3.66, d d, 9.8,3.6$ & & \\
\hline $4^{\prime \prime}$ & 73.96 & $3.31, m$ & & \\
\hline $5^{\prime \prime}$ & 70.66 & $4.26, m$ & & $\mathrm{H}-1^{\prime \prime}, \mathrm{H}-6^{\prime \prime}$ \\
\hline \multicolumn{5}{|c|}{$\mathrm{CH}_{3}$} \\
\hline $6^{\prime \prime}$ & 17.99 & $1.14, d, 6.2$ & & \\
\hline
\end{tabular}

curve induced by the cumulative addition of $\mathrm{Ca}^{2+}(p>0.05$, two way ANOVA followed by Holm-Sidak test, $n=7$ ), but significantly decreased the contractile responses to $46.98 \pm 7.78 \%$ of a reference $\mathrm{K}^{+}$-induced contraction when $\mathrm{Ba}^{2+}$ was added instead of $\mathrm{Ca}^{2+}$ in the bath solution $(p<0.001$, two way ANOVA followed by HolmSidak test, $n=6$ ). In contrast, at the highest concentration of $600 \mu \mathrm{g} / \mathrm{mL}$, EAF significantly reduced the magnitude of the contractile response induced by the addition of either $\mathrm{Ca}^{2+}$ or $\mathrm{Ba}^{2+}$ to $10.41 \% \pm 1.13 \%$ and $25.34 \pm 3.93 \%$, respectively, in comparison with a reference $\mathrm{K}^{+}$-induced contraction $(p<0.001$, Two way, HolmSidak, $n=5-6$ ). Verapamil, a well-known blocker of L-type $\mathrm{Ca}^{2+}$ channels employed at this experimental protocol as positive control, similarly reduced the contractile response induced by the addition of $\mathrm{Ba}^{2+}$ to $9.77 \pm 2.29 \%$ in comparison with a reference $\mathrm{K}^{+}$-induced contraction (Fig. 5).

\subsection{Effects of bioactive fraction (EAF) on the concentration-response curves to $\mathrm{KCl}$ in OVA-challenged rat tracheal rings}

Concentration-response curves in $\mathrm{KCl}(10-140 \mathrm{mM})$-stimulated tracheal rings from OVA-challenged animals (group II) showed significantly increased contractile responses in comparison with the concentration-response curves observed in tracheal rings obtained from saline-challenged OVA-sensitized animals (group I) $(p<0.001$, Holm Sidak, $n=6,12)$. Treatment with EAF $(150 \mathrm{mg} / \mathrm{kg}$; Group III) before the antigen challenge in OVA-sensitized rats inhibited the establishment of a tracheal hyperresponsive phenotype under contractile stimuli with $\mathrm{KCl}$. Indeed, $E_{\max }$ value was $0.94 \pm 0.007 \mathrm{~g}$ $(n=7)$ for EAF-treated antigen-challenged rats, values that did not differ significantly $(p>0.05$, Holm Sidak) from those observed in tracheal preparations from saline-challenged OVA-sensitized animals of group ( $0.84 \pm 0.10 \mathrm{~g}, n=12$ ) (Fig. 6).

\subsection{Effects of bioactive fraction (EAF) on total and differential cell count in BALF of OVA-challenged rats}

The total number of leukocytes and the alteration of the cellular components in BALF of rats were evaluated. The total leukocytes in 
Table 2

Antioxidant activity of EEHC and fractions on scavenging of DPPH radical $\left(\mathrm{IC}_{50}\right)$.

\begin{tabular}{|c|c|c|c|c|c|c|c|c|c|}
\hline Concentration $(\mu \mathrm{g} / \mathrm{mL})$ & 1.0 & 2.0 & 4.0 & 5.0 & 10.0 & 50.0 & 100.0 & 1000.0 & $\mathrm{IC}_{50}$ \\
\hline EEHC & $18.0 \%$ & $29.4 \%$ & $64.2 \%$ & $83.8 \%$ & - & - & $99.7 \%$ & $99.8 \%$ & $3.07 \pm 0.18$ \\
\hline DF & $1.3 \%$ & - & - & $5.8 \%$ & $10.7 \%$ & $45.7 \%$ & $70.2 \%$ & $99.6 \%$ & $66.3 \pm 6.9$ \\
\hline DEAF & $0.5 \%$ & - & - & $6.4 \%$ & $13.4 \%$ & $73.8 \%$ & $94.8 \%$ & $99.9 \%$ & $34.0 \pm 0.24$ \\
\hline EAF & $11.9 \%$ & - & - & $49.6 \%$ & $85.5 \%$ & $96.9 \%$ & $99.5 \%$ & $99.6 \%$ & $5.05 \pm 1.5$ \\
\hline MF & $11.5 \%$ & $18.6 \%$ & $37.8 \%$ & $49.2 \%$ & - & - & $99.5 \%$ & $99.6 \%$ & $5.12 \pm 0.73$ \\
\hline TROLOX & $24.5 \%$ & $41.8 \%$ & $51.8 \%$ & $86.5 \%$ & - & - & $99.8 \%$ & $99.9 \%$ & $2.6 \pm 0.23$ \\
\hline
\end{tabular}

Each value represents the mean value \pm S.E.M determined in triplicate.
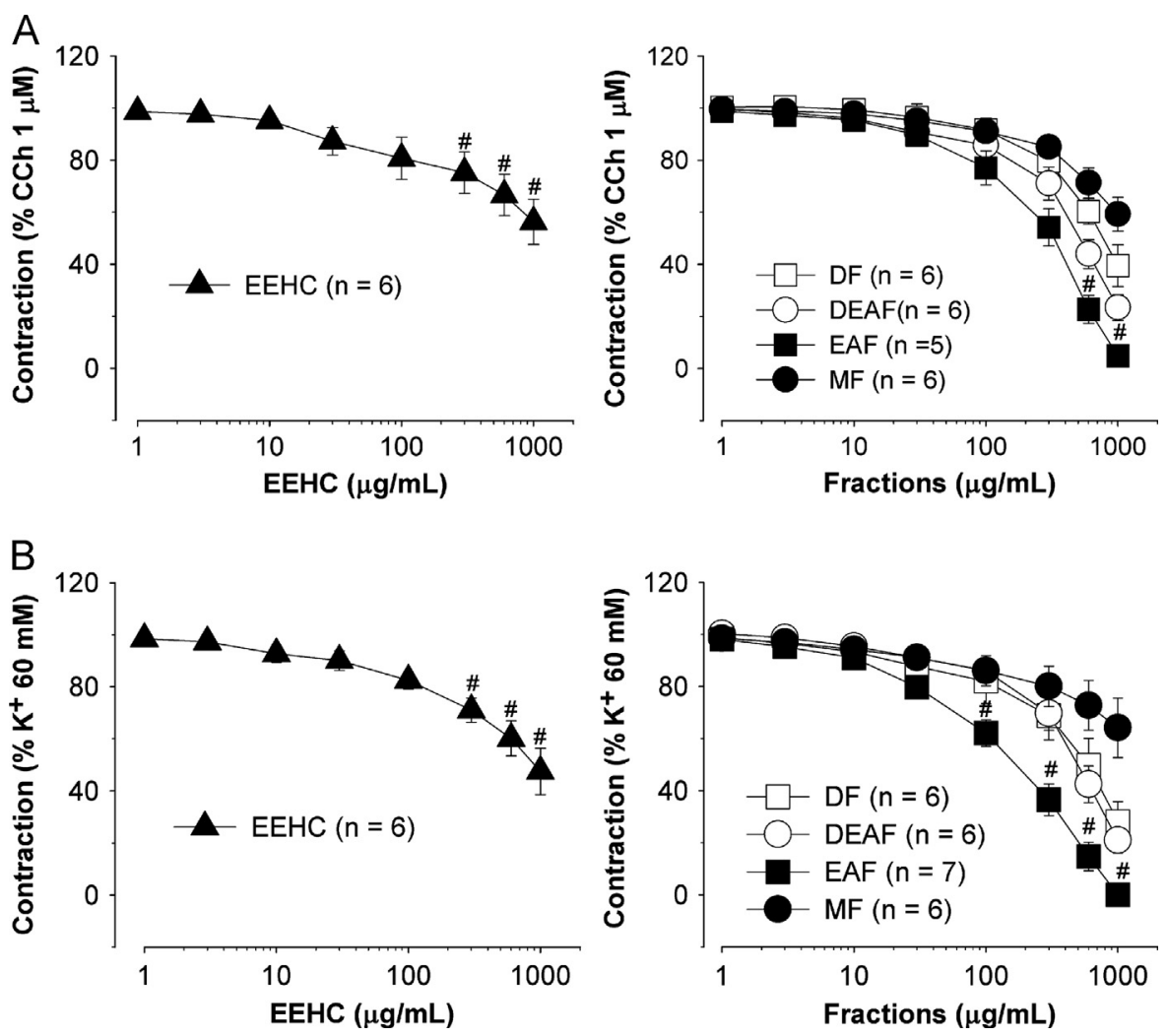

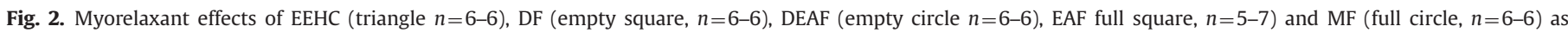

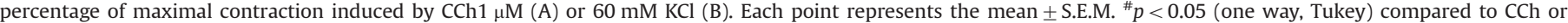
$\mathrm{K}^{+}$-induced initial contraction.

Table 3

Maximal relaxations values for the effects of EEHC, DF, DEAF, EAF and MF in $\mathrm{K}^{+}$or Carbachol-induced contraction on tracheal rings from rats.

\begin{tabular}{lcc}
\hline Sample $(1000.0 \mu \mathrm{g} / \mathrm{mL})$ & \multicolumn{2}{l}{ Relaxation } \\
\cline { 2 - 3 } & $\mathrm{CCh}(1 \mu \mathrm{M})$ & $\mathrm{KCl}(60 \mathrm{mM})$ \\
\hline EEHC & $43.7 \pm 8.7$ & $52.5 \pm 8.9$ \\
DF & $60.5 \pm 8.0$ & $71.9 \pm 7.7$ \\
DEAF & $76.6 \pm 4.9$ & $79.1 \pm 4.8$ \\
EAF & $95.2 \pm 2.9$ & $100.0 \pm 4.1$ \\
MF & $40.8 \pm 6.6$ & $35.9 \pm 11.4$ \\
\hline
\end{tabular}

Maximal relaxations values for effects induced by EEHC and its fractions are the mean \pm S.E.M. percentage of the $\mathrm{K}^{+}$or CCh-induced contraction.

OVA-challenged animals (group II) were remarkably increased as compared to the OVA-sensitized group ( $p<0.001$, test $t$ ). In particular, OVA caused a significant increase in neutrophils (from $0.05 \pm 0.02$ $\left(\times 10^{3}\right.$ cells $\left./ \mathrm{mm}^{3}, n=6\right)$ to $0.50 \pm 0.1\left(\times 10^{3}\right.$ cells $\left.\left./ \mathrm{mm}^{3}, n=7\right)\right)$ and eosinophils (from $0.02 \pm 0.007\left(\times 10^{3}\right.$ cells $\left./ \mathrm{mm}^{3}, n=6\right)$ to $0.09 \pm 0005$

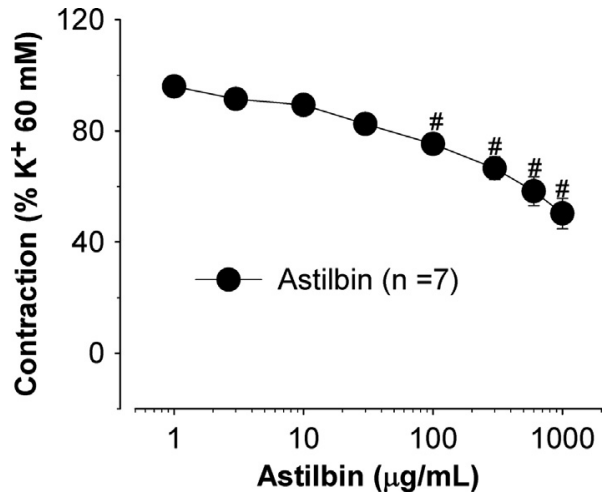

Fig. 3. Myorelaxant effect of astilbin (full circle, $n=7$ ) as a percentage of maximal contraction induced by $60 \mathrm{mM} \mathrm{KCl}$. Each point represents the mean \pm S.E.M. ${ }^{\#} p<0.05$ (one way, Tukey) compared to $\mathrm{K}^{+}$-induced initial contraction.

$\left(\times 10^{3}\right.$ cells $\left./ \mathrm{mm}^{3}, n=7\right)$ ). The leukocytosis was significantly inhibited by the pretreatment with $150 \mathrm{mg} / \mathrm{kg}$ of EAF in the asthma-induced rats group (III) $(p<0.001, n=5$, unpaired t test). In particular, this 
fraction significantly decreased the eosinophilia and neutrophilia $(p<0.05$, Rank Sum) (Fig. 7).

\section{Discussion}

This study evaluated the pharmacological profile of Hymenaea courbaril on the contractile responses of rat isolated trachea, as well as its potential antioxidant and anti-inflammatory activity, through an interdisciplinary study guided by the myorelaxant activity of the EEHC.

EEHC and its chromatographic fractions showed enhanced free radical scavenging activity in the DPPH assay. Based on the action mechanism of DPPH reduction associated with the knowledge of the main chemical class secondary metabolites present in Hymenaea courbaril, it is suggested that antioxidant activity of this plant is related to the presence of compounds with phenolic hydroxyls such as astilbin, which was presently isolated from the active fraction EAF (Brandy-Williams et al., 1995; Mensor et al., 2001). This antioxidant potential attributed to Hymenaea courbaril is an interesting finding, since the release of reactive oxygen species has been associated with airway hyperresponsiveness observed in asthmatics process (Jarjour et al., 1992).

The muscarinic agonist CCh evokes contractions by means of pharmacomechanical coupling that involves $\mathrm{Ca}^{2+}$ release from its internal stores located at the sarcoplasmatic reticulum. Such effect occurs in response to the activation of ROCCs (Himpens and Somlyo,

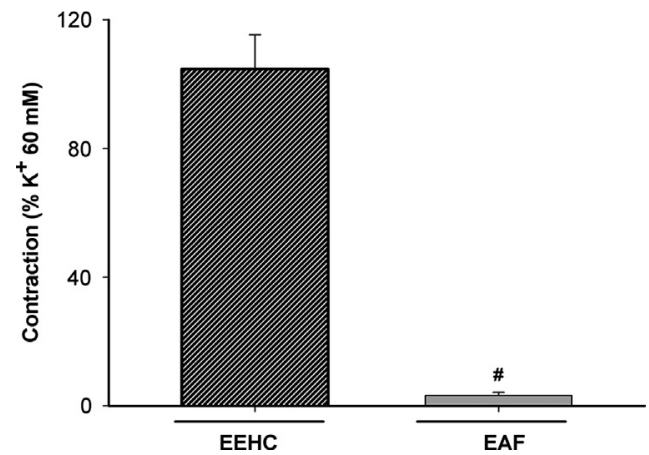

Fig. 4. Effect of the addition of $60 \mathrm{mM} \mathrm{K}^{+}$to trachea rings previously exposed to $\mathrm{EEHC}(n=4)$ or EAF $(n=7)$. After concentration-response curves to EEHC or EAF, the tissue was submitted to repeated washes followed by a new $\mathrm{K}^{+}$-induced contraction. The values represents the mean \pm S.E.M. $(p<0.001, t$ test $)$
1988). On the other hand, a high- $\mathrm{K}^{+}$-induced contraction in a smooth muscle cell is considered as being initiated by electromechanical coupling, which involves the activation of VOCCs and subsequent transmembrane influx of $\mathrm{Ca}^{2+}$ (Kirkpatrick et al., 1975; Somlyo et al., 1999). In this study, the extract of Hymenaea courbaril showed the ability to induce relaxant effects in tracheal rings contracted as by pharmacomechanical as by eletromechanical pathways, being EAF the fraction with highest efficacy.

The EAF fraction similarly relaxed tracheal rings contracted either with $\mathrm{K}^{+}$or $\mathrm{CCh}$, but it was more potent to inhibit $\mathrm{K}^{+}$-induced contractions. Interestingly, its inhibitory effects against $\mathrm{K}^{+}$-induced contractions appeared irreversible, at least considering the interval (30 min) allowed to tissue recovery after repeated washings. Although not addressed in the present study, such finding could not be explained based on a putative toxic effect induced by this fraction since the contractions induced by $\mathrm{CCh}$ were completely recovered after similar procedures. Indeed, it is possible that EAF has a preferential inhibitory action on the contractile response elicited electromechanically. Such hypothesis is supported by the fact that $\mathrm{EAF}$ (at $300 \mu \mathrm{g} / \mathrm{mL}$ ) was more potent in inhibiting the contractions induced by the cumulative addition of $\mathrm{Ba}^{2+}$, an ion that is poorly permeable through ROCCs but with selective flow through VOCCs (Murray and Kotlikoff, 1991; Cuthbert et al., 1994). On the other hand,

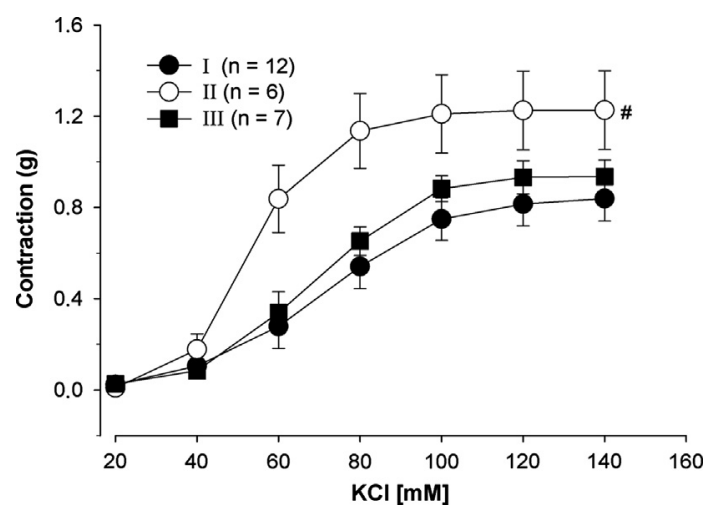

Fig. 6. Inhibitory effect of EAF treatment on the development of airway hyperresponsiveness on OVA-sensitized rats challenged with sensitizing antigen. Concentration-effect curves for $\mathrm{KCl}(10-140 \mathrm{mM})$ in tracheal rings from OVA-sensitized animals challenged with saline (I-full circle, $n=12$ ), OVA-sensitized animals challenged with OVA (II-empty circle, $n=6$ ) and OVA-sensitized animals challenged with OVA after pretreatment with EAF (III-full square, $n=7$ ) ${ }^{*} p<0.05$, two way, Holm Sidak)
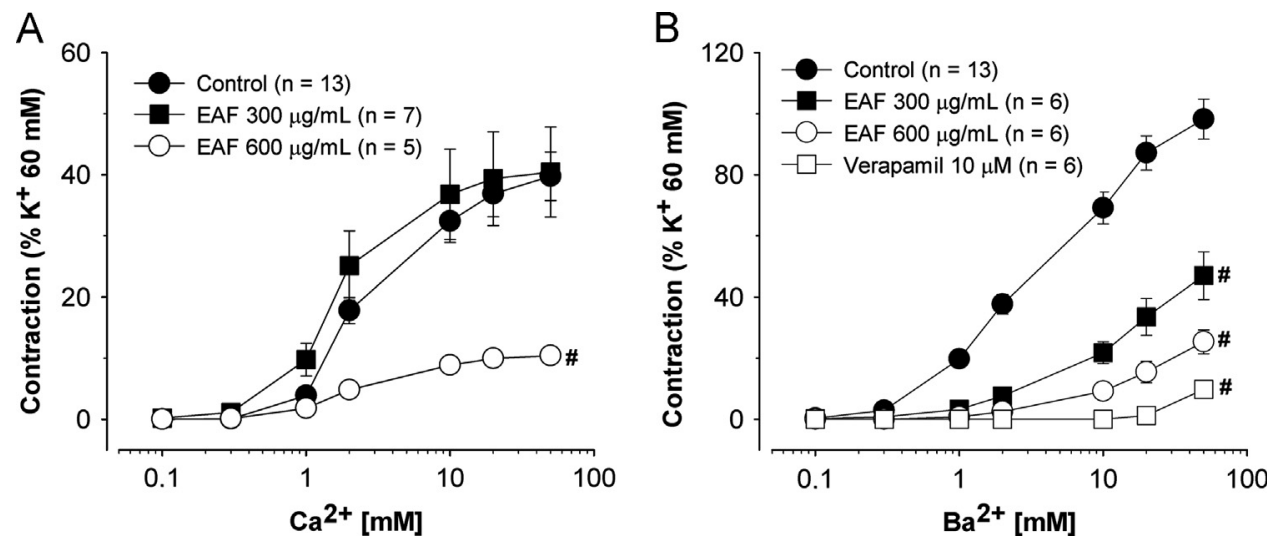

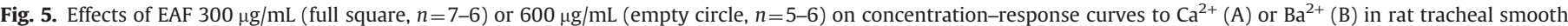

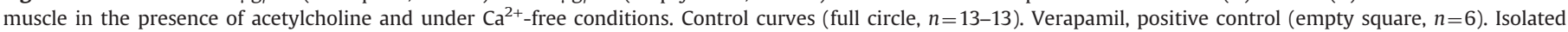

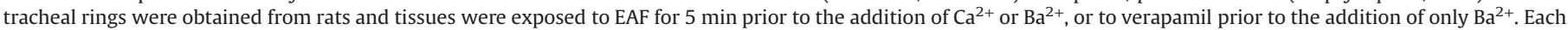
point represents the mean \pm S.E.M. ${ }^{*} p<0.001$ compared to control (Holm- Sidak). 
A

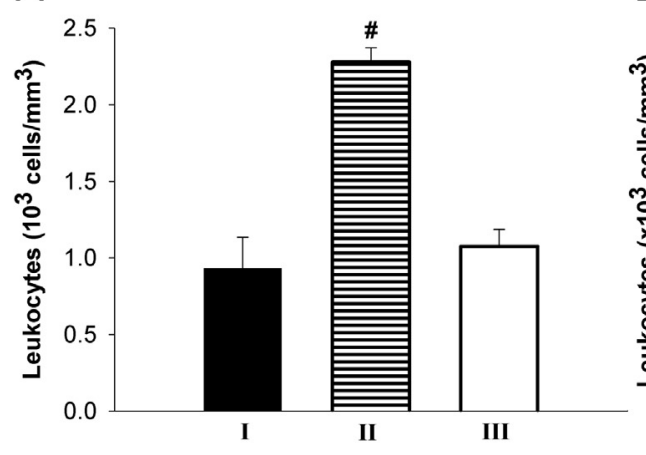

B

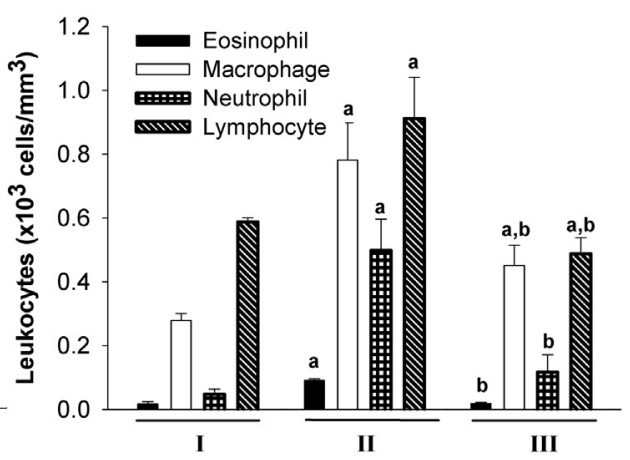

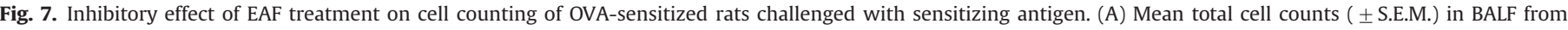

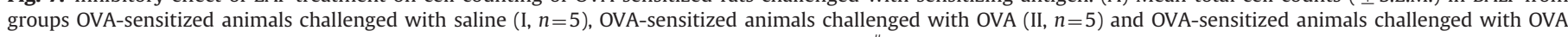

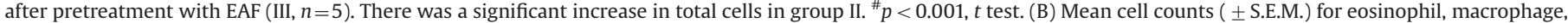

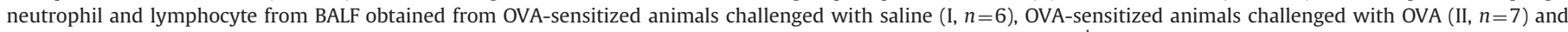
OVA-sensitized animals challenged with OVA after pretreatment with EAF (III, $n=7$ ). ${ }^{\mathrm{a}} p<0.001$ compared to I group, ${ }^{\mathrm{b}} p<0.001$ compared to II group, Rank Sum.

at a higher concentration of $600 \mu \mathrm{g} / \mathrm{mL}$, EAF appears to inhibit contractions induced by either ROCC- or by VOCC-elicited pathways.

The establishment of an inflammation environment in airways is often related in asthmatic subjects, caused by multifactorial and complex interactions involving several cell types that modulate the inflammatory process including the release of cytokines, chemokines, growth factors and other mediators. Such interactions certainly influence the development of airway hyperresponsiveness (Fernandes et al., 2003). Experimental models of antigen-challenge in animals are able to develop a clinical syndrome that closely resembles allergic asthma in humans, which may include eosinophilic lung inflammation and airway hyperresponsiveness (Epstein, 2004). Herein, the hyperresponsive phenotype was replicated in rats as a reliable method to induce airway inflammation. The increased levels of white blood cells in BALF reinforce such aspect. Interestingly, pretreatment of OVA sensitized antigen-challenged animals with EAF by an oral route of administration prevented the establishment of airway hyperresponsiveness, as well as it reduced the total number of white blood cells, particularly eosinophils and neutrophils in bronchoalveolar lavage. Such effect for Hymenaea courbaril has not been reported hitherto and we suggest, that, in vivo, EAF may serve as antiinflammatory agent.

Astilbin showed myorelaxant activity on rat trachea, since it was able to reverse by approximately $50 \%$ of the $\mathrm{K}^{+}$-induced contraction. This finding reveals that the presence of this compound, at least in part, explains the myorelaxant properties of EAF. Although not presently tested in other assays, it is possible that it is also involved in the anti-inflammatory and antioxidant activities of EAF. As a matter of fact, it was already reported that astilbin has inhibitory effects on pro-inflammatory cytokines expression by suppressing macrophage and lymphocyte functions, including cell migration (Huang et al., 2011; Cai et al., 2003), and application as antioxidant agent is a promising feature described for this compound (Vijayalakshmi et al., 2011). Igarashi et al. (1996) also reported the direct in vivo antioxidant effects of astilbin in rats.

\section{Conclusion}

This study provided scientific basis that Hymenaea courbaril presents potential antioxidant, myorelaxant and anti-inflammatory, which support its use in folk medicine to treat inflammatory airway diseases, such as asthma. However, further studies are necessary to characterize its bioactive fraction, EAF, as well as its mechanism of action in the respiratory tract.

\section{Acknowledgments}

The authors thank the Brazilian agencies CNPq, CAPES, FUNCAP, PRONEX for fellowships and financial support and, CENAUREMNUFC for providing the NMR spectra.

\section{References}

Aguiar, J.C.D., Santiago, G.M.P., Lavor, P.L., Veras, H.N.H., Ferreira, Y.S., Lima, M.A.A., Arriaga, A.M.C., Lemos, T.L.G., Lima, J.Q., de Jesus, H.C.R., Alves, P.B., Braz-Filho, R., 2010. Chemical constituents and larvicidal activity of Hymenaea courbaril fruit peel. Natural Product Communications 5, 1977-1980.

Brandy-Williams, W., Cuvelier, M.E., Berset, C., 1995. Use of a free radical method to evaluate antioxidant activity. LWT-Food Science and Technology 28, 25-30.

Cai, Y., Chen, T., Xu, Q., 2003. Astilbin suppresses delayed-type hypersensitivity by inhibiting lymphocyte migration. Journal of Pharmacy and Pharmacology 55, 691-696.

Campos, M.A.A., Uchida, T., 2002. Influência do sombreamento no crescimento de mudas de três espécies amazônicas. Pesquisa Agropecuária Brasileira 37 281-288.

Cartaxo, S.L., Souza, M.M.A., Albuquerque, U.P., 2010. Medicinal plants with bioprospecting potential used in semi-arid Northeastern Brazil. Journal of Ethnopharmacology 131, 326-342.

Cecílio, A.B., Faria, D.B., Oliveira, P.C., Caldas, S., Oliveira, D.A., Sobral, M.E.G., Duarte M.G.R., Moreira, C.P.S., Silva, C.G., Almeida, V.L., 2012. Screening of Brazilian medicinal plants for antiviral activity against rotavirus. Journal of Ethnopharmacology 141, 975-981.

Cunningham, A., Martin, S.S., Langenheim, J.H., 1974. Labd-13-en-8-ol-15-oic acid in the trunk resin of amazonian Hymenaea courbaril. Phytochemistry 13, 294-295.

Cuthbert, N.J., Gardiner, P.J., Nash, K., Poll, C.T., 1994. Roles of $\mathrm{Ca}^{2+}$ influx intracellular and $\mathrm{Ca}^{2+}$ release in agonist-induced contractions in guinea pig tracheal. American Journal of Physiology 266, 620-627.

Epstein, M.M., 2004. Do mouse models of allergic asthma mimic clinical disease? International Archives of Allergy and Immunology 133, 84-100.

Fernandes, D.J., Richard, W.M., Lakser, O., Dowell, M., Stewart, A.G., Solway, Y.J. 2003. Airway hyperresponsiviness: from molecules to bedside. Invited Review: do inflammatory mediators influence the contribution of airway smooth muscle contraction to airway hyperresponsiviness in asthma? Journal of Applied Physiology 95, 844-853.

Himpens, B., Somlyo, A.P., 1988. Free-calcium and force transients during depolarization and pharmacomechanical coupling in guinea-pig smooth muscle. Journal of Physiology 395, 507-530.

Huang, H., Cheng, Z., Haiming, S., Xin, W., Wang, T.T.Y., Yu, L.L., 2011. Isolation and characterization of two flavonoids, engeletin and astilbin, from the leaves of Engelhardia roxburghiana and their potential anti-inflammatory properties. Journal of Agricultural and Food Chemistry 59, 4562-4569.

Igarashi, K., Uchida, Y., Murakami, N., Mizutani, K., Masuda, H., 1996. Effect of astilbin in tea processed from leaves of Engelhardtia chrysolepis on the serum and liver lipid concentrations and on the erythrocyte and liver antioxidative enzyme activities of rats. Bioscience, Biotechnology and Biochemistry 60 513-515.

Jayaprakasam, B., Alexander-Lino, R.L., Dewitt, D.L., Nair, G., 2007. Terpenoids from Stinking toe (Hymenaea courbaril) fruits with cyclooxigenase and lipid peroxidation inhibitory activities. Food Chemistry 105, 485-490.

Jarjour, N.N., Busse, W.W., Calhoun, W.J., 1992. Enhanced production of oxygen radicals in nocturnal asthma. The American Review of Respiratory Disease, 146. 
Keiji, T., Kenji, K., Yoshio, K., Tohru, M., Isao, M., 1999. Tyrosinase inhibitors from the pericarp of Jatoba (Hymenaea courbaril L.). Natural Medicines 53, 15-21.

Kirkpatrick, C.T., Jenkinson, H.A., Cameron, A.R., 1975. Interaction between drugs and potassium-rich solutions in producing contraction in bovine tracheal smooth muscle: studies in normal and calcium-depleted tissues. Clinical and Experimental Pharmacology and Physiology 2, 559-570.

Lee, Y.T., Langenheim, J.H., 1975. Systematics of the Genus Hymenaea (Leguminosae, Caesalpinioideae, Detarieae). vol. 69. University of California Publications in Botany.

Lucas-Filho, M.D., Silva, G.C., Cortes, S.F., Mares-guia, T.R., Pérpetua-Ferraz, V., Serra, C.P., Braga, F.C., 2010. ACE inhibition by astilbin isolated from Erythroxylum gonocladum (Mart.) O.E. Schulz. Phytomedicine 17, 383-387.

Marsaioli, A.J., Leitão-Filho, H.F., Campello, J.P., 1975. Diterpenes in the bark of Hymenaea courbaril. Phytochemistry 14, 1882-1883.

Matos, F.J.A., 2009. Introdução à fitoquímica experimental. Fortaleza, 47-71.

Mensor, L.L., Menezes, F.S., Leitão, G.G., Reis, A.S., dos Santos, T.C., Coube, C.S., Leitão, S.G., 2001. Screening of Brazilian plant extracts for antioxidant activity by the use of DPPH free radical method. Phytotherapy Research 15, 127-130.
Murray, R.K., Kotlikoff, M.I., 1991. Receptor-activated calcium influx in human airway smooth muscle cells. Journal of Physiology 435, 123-144.

Nogueira, R.T., Shepherd, G.J., Laverde Jr., A., Marsaioli, A.J., Imamura, P.M., 2001. Clerodane-type diterpenes from the seed pods of Hymenaea courbaril var. stilbocarpa. Phytochemistry 58, 1153-1157.

Nogueira, R.T., Giacomini, R.A., Shepherd, G.J., Imamura, P.M., 2002. A new entclerodane diterpene from Hymenaea courbaril var. altissima. Journal of the Brazilian Chemical Society 13, 389-391.

Regasini, L.O., Fernandes, D.C., Castro-Gamboa, I., Silva, D.H.S., Furlan, M., Bolzani, V. S., 2008. Constituintes químicos das flores de Pterogyne nitens (Caesalpinioideae) 31, 802-806.

Somlyo, A.P, Wu, X., Lalker, L.A., Somlyo, A.V., 1999. Pharmacomecanical coupling: the role of calcium, G-proteins, kinases and phosphatase. Reviews of Physiology, Biochemistry and Phamacology 134, 201-234.

Vijayalakshmi, A., Ravichandiran, V., Jayakumari, S., Velraaj, M., 2011. Antioxidant and antioconvulsant activity of astilbin, a flavonoid glycoside from the rhizome of Smilax China Linn. Journal of Pharmacy Research 4, 561-563. 